\title{
Anticancer drugs utilization for initiation phase of breast and cervical cancers chemotherapies in a Nigerian tertiary hospital
}

\author{
Maxwell Ogochukwu Adibe ${ }^{1 *}$, Deborah Oyine Aluh', Hadiza Usman Ma'aji² \\ ${ }^{1}$ Department of Clinical Pharmacy and Pharmacy management, University of Nigeria Nsukka, Nsukka, Enugu State, Nigeria. \\ ${ }^{2}$ Department of Clinical Pharmacy and Pharmacy Practice, Ahmadu Bello University, Zaria, Kaduna State, Nigeria.
}

\begin{tabular}{l}
\hline ARTICLE INFO \\
\hline Received on: 29/07/2018 \\
Accepted on: 22/02/2019 \\
Available online: $30 / 03 / 2019$ \\
\\
\hline Key words: \\
Drug utilization, Nigeria, \\
breast cancer, cervical cancer, \\
chemotherapy.
\end{tabular}

\section{INTRODUCTION}

Cancer is the second leading cause of death globally and was responsible for 8.8 million deaths in 2015 (World Health Organization, 2017). Approximately $70 \%$ of these deaths from cancer occur in low- and middle-income countries (World Health Organization, 2017). It is projected that by $2030,70 \%$ of all new cases of cancer will be found in developing countries (Boyle and Levin, 2014). In Nigeria, about 100,000 new cases of cancer occur

\section{${ }^{*}$ Corresponding Author}

Maxwell Ogochukwu Adibe, Department of Clinical Pharmacy and Pharmacy management, University of Nigeria Nsukka, Nsukka, Enugu State,Nigeria.E-mail: maxwell.adibe@unn.edu.ng every year, with high case fatality ratio (Ferlay et al., 2010). This increase in the incidence of cancer in Nigeria can be attributed to increasing life expectancy, reduced risk of death from infectious diseases, increased prevalence of smoking, physical inactivity, obesity, and changing dietary pattern (Sylla and Wild, 2012).

Chemotherapy remains one of the integral components in themanagement of cancer. They are eitherused alone or in combination with other modalities of management such as radiotherapy and surgery (Dave et al., 2014). The prescription pattern of anticancer drugs has changed significantly in recent years because of a better understanding of the pathophysiology of carcinomas, as well as the introduction of newer drugs (Dave et al., 2014). Significant variation in the response rate of individual anticancer drugs, availability of different regimens, and intolerability of combination regimens 
necessitate observation and evaluation of cancer chemotherapy. Chemotherapy-induced nausea and vomiting is linked as an adverse reaction with a chemotoxic agent. Delayed nausea and emesis were reported in discharged patients after few days of chemotherapy (Gündüz and Gülbas, 2012). Nausea and vomiting are the major side effects for $70 \%-80 \%$ of patients receiving chemotherapy (Navari, 2007) and with 10\%-44\% experiencing anticipatory type of emesis (The Italian Group for Antiemetic Research, 1997). Optimal antiemetic use in chemotherapy has the potential to lower the overall healthcare cost by providing cost-effective treatment. Selection of anticancer drugs for initiation of chemotherapy is an important determinant of whether the patient would continue the chemotherapy, switch to another agent, or discontinue after the first course of chemotherapy. Therefore, it is important that attention should be given to the initiating agents, their side effects, and general safety of the patients.

Drug Utilization Research encompasses a drug review against predetermined criteria that results in changes to drug therapy when these criteria are not met. It involves a comprehensive review of patients' prescription and medication data before, during, and after dispensing to ensure appropriate medication decisionmaking and positive patient outcomes. Drug Utilization Research focuses on reducing serious preventable drug-related morbidity and complicated regimens. It mainly compares the particular drug prescribed by the physician with the widely used standard practice guidelines and quality assurance with therapy (Fulda et al., 2004). The quality of therapy and the cost of drug use are also important parameters considered in drug utilization research (Raveh et al., 2006). As a quality assurance measure, Drug Utilization Research programs provide corrective action, prescriber feedback, and further evaluations. They serve to identify associated problems, the potential for abuse, and provide feedback to prescribers so as to encourage the rational use of anticancer drugs. Therefore, the objective of this study was to assess the utilization of anticancer drugs at the first course of breast and cervical cancers chemotherapies over a 5-year period (2012-2016) in the Oncology unit of Ahmadu Bello University Teaching Hospital (ABUTH), Shika, Kaduna State.

\section{METHODS}

\section{Study setting}

The study was carried out in Oncology and Radiotherapy unit of ABUTH. ABUTH is a tertiary institution that is situated in Shika, Kaduna State. It is a national center of excellence for oncology. It was established for the sole purpose of providing health care services for both Nigerians and non-Nigerians, training of medical students, and for research purposes.

\section{Study design}

This retrospective study audited 1,000 randomly selected folders (100 folders each for breast and cervical cancer per year), resulting in 500 folders each for breast and cervical cancer patients.

\section{Inclusion and exclusion (Eligibility) criteria}

Data of female patients who were diagnosed with breast or cervical cancers and who were placed on chemotherapy were included in the study. Only the anticancer and antiemetic drugs administered at the first course for initiation of chemotherapy were extracted for this study.

Data of patients who were diagnosed with breast or cervical cancer but required surgical intervention, radiotherapy, or other management modalities were excluded.

\section{Data collection}

Patients' demographics, anticancer and antiemetic drugs administered, dosage form, and strength were abstracted and documented. The drug utilization was measured using number of the dosage units (DUs) (tables, vials, or ampules) of each of the anticancer and antiemetic drugs. DU measurement was used because most of the cancer drugs do not have defined daily dose, which is usually used as a measurement parameter for drug utilization (Wessling and Boethius, 1990).

\section{Data analysis}

Descriptive analyses were conducted using SPSS version 20 (IBM Corporation, Armonk, NY). The results were presented as DUs per year, DUs in 5 years, and DUs per cancer type.

The DUs were calculated as total number of the utilized doses (mg) divided by the minimum marketed dose (mg) of the drug. When a drug is marketed in different dosage strengths or units, the smallest dosage unit is considered one DU and others will be multiples of the smallest unit (Chauvin et al., 2001; Merlo et al., 1996; Ried and Johnson, 1992). This represents the number of DUs of anticancer or antiemetic drugs utilized in the initiation of chemotherapy of 100 breast or cervical cancer patients per year. The following dosage units of each of the drugs is equivalent to one DU: 5-Fluorouracil $500 \mathrm{mg}$, Cisplatin $50 \mathrm{mg}$, Carboplatin 150 $\mathrm{mg}$, Cyclophosphamide $500 \mathrm{mg}$, Epirubicin $50 \mathrm{mg}$, Doxorubicin $50 \mathrm{mg}$, Docetaxel $20 \mathrm{mg}$, Paclitaxel $100 \mathrm{mg}$, Gemcitabine 1,000 $\mathrm{mg}$, Zoledronic acid $4 \mathrm{mg}$, Vincristine $1 \mathrm{mg}$, Dacarbazine $200 \mathrm{mg}$, Metoclopramide $10 \mathrm{mg}$, Ondansetron $8 \mathrm{mg}$, Granisetron $1 \mathrm{mg}$, and Dexamethasone $4 \mathrm{mg}$.

\section{Ethical considerations}

The study protocol (ABUTH/HREC/TRG/36) was approved by ABUTH Health Research Committee. The data collected were treated with the utmost confidentiality both during and after the study.

\section{RESULTS}

The patients were between the age range of 30 and 89 years. Majority of patients (31\% vs. 29\%) were in the age bracket of 40-49 years for breast and cervical cancers, respectively. Generally, the proportion of one, two, and more than two anticancers drugs per prescription were $31 \%, 49 \%$, and $20 \%$, respectively. About $79 \%$ and $97 \%$ of the anticancer and antiemetic drugs, respectively, were prescribed by their generic names. All the anticancer drugs (100\%) and about $93 \%$ of antiemetic drugs prescribed were injectables. About $7 \%$ of the orally administered antiemetic were prescribed to prevent or manage delayed nausea and vomiting. Cisplatin, 5-Fluorouracil, Paclitaxel, Carboplatin, and Docetaxel accounted for about $76 \%$ of all the anticancer drugs that were used for the initiation of chemotherapy for both breast and cervical cancers. Dexamethasone and Metoclopramide accounted for about $73 \%$ of all the antiemetic drugs utilized within the study period for both breast and cervical cancers (Table 1). 
The most utilized anticancer drugs for initiation of chemotherapy of 500 patients with breast or cervical cancer within the study period for breast versus cervical cancer were Cisplatin (1,140 vs. 624 DUs), 5-Fluorouracil (860 vs. 292 DUs), and Paclitaxel (709 vs. 319 DUs). The widely utilized antiemetic agents for prevention or management of nausea and vomiting at the initiation of chemotherapy of 500 patients with breast or cervical cancer during the study periods for breast versus cervical cancer were Dexamethasone (1,940 vs. 1,260 DUs), Metoclopramide (1,220 vs. 320 DUs), and Ondansetron (1,080 vs. 300 DUs). Cisplatin was the most frequently prescribed drug for both breast and cervical cancer. Dexamethasone was the most frequently prescribed antiemetic for both breast and cervical cancer. Carboplatin and Zoledronic acid were only used in breast cancer and cervical cancer, respectively, (Table 2).

Year by year analysis showed a generally increasing trend in the utilization of all the anticancer and antiemetic drugs throughout the study periods. Cisplatin showed an all year highest utilization compared to other anticancer drugs, except in 2016 where it was slightly lower than Paclitaxel, as shown in Table 3 and Figure 1. Dexamethasone was the most utilized antiemetic drug throughout the study period (Table 3; Fig. 2).

\section{DISCUSSION}

Worldwide, breast cancer followed by cervical cancer is the most common female malignancy in both incidence and mortality and results in approximately 275,000 deaths annually. More than $85 \%$ of new cases are diagnosed in economically disadvantaged people (Wiebe et al., 2012). It has been stated that breast cancer is one of the most common neoplasms in women and is a leading cause of cancer-related deaths worldwide

Table 1. Percentage anticancer and antiemetic drugs utilization by 1,000 patients in 5 years.

\begin{tabular}{|c|c|c|}
\hline Drug & DUs/1,000 patient & Percentage \\
\hline \multicolumn{3}{|l|}{ Anticancer drugs } \\
\hline Cisplatin & 1,764 & 25.7 \\
\hline 5-Fluorouracil & 1,152 & 16.8 \\
\hline Paclitaxel & 1,028 & 15.0 \\
\hline Carboplatin & 706 & 10.3 \\
\hline Docetaxel & 540 & 7.9 \\
\hline Cyclophosphamide & 508 & 7.4 \\
\hline Doxorubicin & 358 & 5.2 \\
\hline Dacarbazine & 292 & 4.3 \\
\hline Epirubicin & 260 & 3.8 \\
\hline Vincristine & 160 & 2.3 \\
\hline Gemcitabine & 88 & 1.3 \\
\hline \multicolumn{3}{|l|}{ Antiemetics } \\
\hline Dexamethasone & 3,200 & 49.08 \\
\hline Metoclopramide & 1,540 & 23.62 \\
\hline Ondansetron & 1,380 & 21.17 \\
\hline Granisetron & 400 & 6.13 \\
\hline \multicolumn{3}{|c|}{$\begin{array}{l}\text { The smallest unit of each of the drugs is as follows: Metoclopramide } 10 \mathrm{mg} \text {, Ondansetron } \\
8 \mathrm{mg} \text {, Granisetron } 1 \mathrm{mg} \text {, Dexamethasone } 4 \mathrm{mg} \text {, 5-Fluorouracil } 500 \mathrm{mg} \text {, Cisplatin } 50 \mathrm{mg} \text {, } \\
\text { Carboplatin } 150 \mathrm{mg} \text {, Cyclophosphamide } 500 \mathrm{mg} \text {, Epirubicin } 50 \mathrm{mg} \text {, Doxorubicin } 50 \\
\mathrm{mg} \text {, Docetaxel } 20 \mathrm{mg} \text {, Paclitaxel } 100 \mathrm{mg} \text {, Gemcitabine } 1,000 \mathrm{mg} \text {, Vincristine } 1 \mathrm{mg} \text {, and } \\
\text { Dacarbazine } 200 \mathrm{mg} \text {. }\end{array}$} \\
\hline
\end{tabular}

(Akram et al., 2012; Amin et al., 2012; Polyak, 2001). Breast and cervical cancers were the focus of this study.

From this study, the age group with the highest prevalence of both cancer cases considered was 40-49 years, this is corroborating the findings of similar studies which reported 41-50 years (Dave et al., 2012; Mugada et al., 2016). It has been postulated that aging-related processes may be responsible for increased cancer prevalence at increased age (Anisimov, 2003; Krtolica and Campisi, 2002).

Table 2. Anticancer and antiemetic drugs utilization by cancer types in 5 years.

\begin{tabular}{lcc}
\hline Drug & Breast cancer & Cervical cancer \\
\hline Anticancer drugs & \multicolumn{2}{c}{ DUs per 500 patients in 5 years } \\
Cisplatin & 1,140 & 624 \\
5-Fluorouracil & 860 & 292 \\
Paclitaxel & 709 & 319 \\
Carboplatin & 706 & 0 \\
Docetaxel & 206 & 302 \\
Gemcitabine & 176 & 84 \\
Cyclophosphamide & 172 & 368 \\
Dacarbazine & 119 & 239 \\
Doxorubicin & 105 & 187 \\
Vincristine & 40 & 120 \\
Epirubicin & 16 & 72 \\
Antiemetics & & \\
Dexamethasone & 1,940 & 1,260 \\
Metoclopramide & 1,220 & 320 \\
Ondansetron & 1,080 & 300 \\
Granisetron & 247 & 153 \\
\hline
\end{tabular}

The smallest unit of each of the drugs is as follows: Metoclopramide $10 \mathrm{mg}$, Ondansetron $8 \mathrm{mg}$, Granisetron $1 \mathrm{mg}$, Dexamethasone $4 \mathrm{mg}$, 5-Fluorouracil $500 \mathrm{mg}$, Cisplatin $50 \mathrm{mg}$, Carboplatin $150 \mathrm{mg}$, Cyclophosphamide $500 \mathrm{mg}$, Epirubicin $50 \mathrm{mg}$, Doxorubicin 50 mg, Docetaxel $20 \mathrm{mg}$, Paclitaxel $100 \mathrm{mg}$, Gemcitabine 1,000 mg, Vincristine $1 \mathrm{mg}$, and Dacarbazine $200 \mathrm{mg}$.

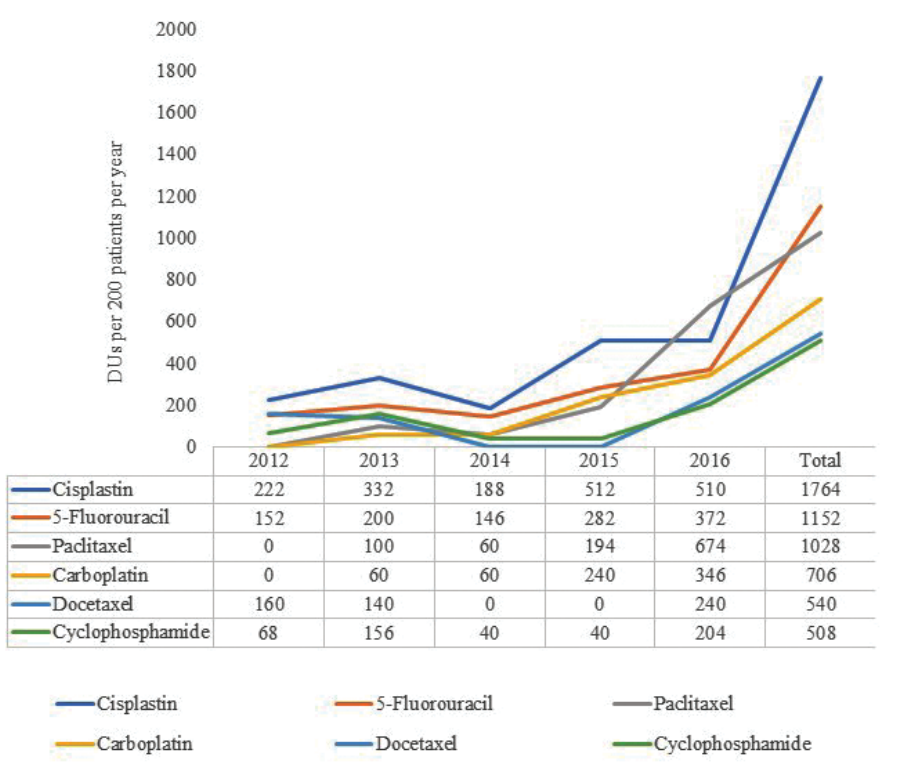

Figure 1. Six most utilized anticancer drugs in 5 years. 
Table 3. Pattern of anticancer and antiemetic drugs utilization per year.

\begin{tabular}{lcccccc}
\hline Drug & $\mathbf{2 0 1 2}$ & $\mathbf{2 0 1 3}$ & $\mathbf{2 0 1 4}$ & $\mathbf{2 0 1 5}$ & $\mathbf{2 0 1 6}$ & Total \\
\hline Anticancer drugs & & \multicolumn{5}{c}{ DUs per 200 patients per year } \\
Cisplastin & 222 & 332 & 188 & 512 & 510 & 1,764 \\
5-Fluorouracil & 152 & 200 & 146 & 282 & 372 & 1,152 \\
Paclitaxel & 0 & 100 & 60 & 194 & 674 & 1,028 \\
Carboplatin & 0 & 60 & 60 & 240 & 346 & 706 \\
Docetaxel & 160 & 140 & 0 & 0 & 240 & 540 \\
Cyclophosphamide & 68 & 156 & 40 & 40 & 204 & 508 \\
Doxorubicin & 36 & 44 & 40 & 70 & 168 & 358 \\
Dacarbazine & 0 & 0 & 56 & 120 & 120 & 292 \\
Epirubicin & 80 & 60 & 0 & 0 & 120 & 260 \\
Vincristine & 0 & 40 & 40 & 40 & 40 & 160 \\
Gemcitabine & 0 & 40 & 0 & 0 & 48 & 88 \\
Antiemetics & & & & & 1,160 & 3,200 \\
Dexamethasone & 400 & 600 & 240 & 800 & 480 & 1,540 \\
Metoclopramide & 200 & 300 & 160 & 400 & 500 & 1,380 \\
Ondasetron & 180 & 280 & 120 & 300 & 180 & 400 \\
Granisetron & 20 & 20 & 20 & 160 & & \\
\hline
\end{tabular}

The smallest unit of each of the drugs is as follows: Metoclopramide $10 \mathrm{mg}$, Ondansetron $8 \mathrm{mg}$, Granisetron $1 \mathrm{mg}$, Dexamethasone $4 \mathrm{mg}$, 5-Fluorouracil $500 \mathrm{mg}$, Cisplatin $50 \mathrm{mg}$, Carboplatin $150 \mathrm{mg}$, Cyclophosphamide $500 \mathrm{mg}$, Epirubicin $50 \mathrm{mg}$, Doxorubicin $50 \mathrm{mg}$, Docetaxel 20 mg, Paclitaxel $100 \mathrm{mg}$, Gemcitabine 1,000 mg, Vincristine $1 \mathrm{mg}$, and Dacarbazine $200 \mathrm{mg}$.

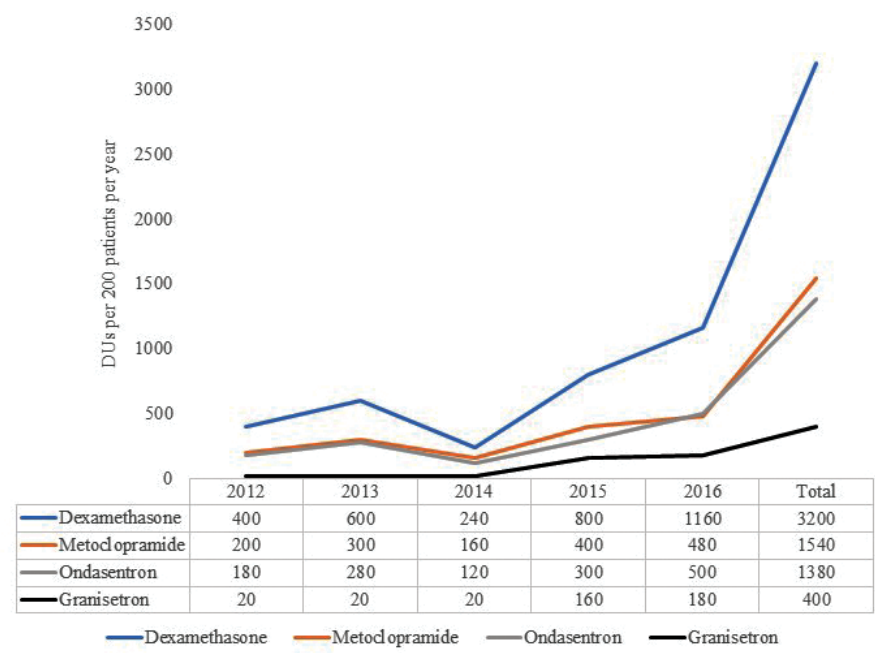

Figure 2. Antiemetics utilization in 5 years.

Chemotherapy is the use of drugs to inhibit or kill proliferating cancer cells while leaving host cells unharmed or at least recoverable (Mayer and Janoff, 2007). Anticancer drugs were mostly prescribed in combination in this study. This finding is consistent with the existing utilization pattern of anticancer drugs (Pentareddy et al., 2015). Two or three anticancer drugs were prescribed in most cases. The average number of anticancer drugs per patient was 1.93 which concurs with findings from a similar study by Mugada et al. (2016) where the average number of cytotoxic drugs per prescription was 1.97. Various modalities such as surgery, radiation therapy, or immunotherapy are also being used for the treatment of cancer. The choice of therapy depends on the location and grade of the tumor, the stage of the disease, and the general state of the patient (Mayer and Janoff, 2007).

Among the anticancer drugs encountered in this study, Cisplatin, a DNA linking anticancer agent was the most utilized, followed by 5-Fluorouracil. These two drugs had also been reported to have the highest number of use in a similar study (Mugada et al., 2016) where their combination was mostly used. Cisplatin followed by 5-Fluorouracil was also the most utilized drug for the treatment of cervical cancer in a study conducted by Pentareddy et al. (2015). However, Cyclophosphamide, 5-Fluorouracil, and Epirubicin combination were mostly used for breast cancer treatment, as was reported by Dave et al. (2014). This combination represents the most basic and effective chemotherapy combination according to the WHO essential drug list and has shown survival benefit (Russo et al., 2013; Silva et al., 2006).

Due to the ability of anticancer agents to kill cells, their actions are not specific to tumor cells only, they also damage normal cells. As a result, they can produce significant side effects in patients and other people exposed to the drugs. The most distressing side effects of cancer chemotherapy are nausea and vomiting. A number of guidelines recommend the use of $5-\mathrm{HT}_{3}$ antagonists as a pharmacological intervention for acute and delayed nausea and vomiting for moderately and highly emetogenic chemotherapy (Vrabel, 2007). Dexamethasone, a corticosteroid was most utilized antiemetic drug in this study and this also is in agreement with similar studies (Dave et al., 2014; Pentareddy et al., 2015). Although Dexamethasone is not approved as an antiemetic, it plays a major role in the prevention of acute and delayed chemotherapy-induced nausea and vomiting and is an integral component of almost all antiemetic regimen (Grunberg, 2007). Dexamethasone is prescribed in different doses at different frequencies for the different durations of days depending on the patient condition 
and severity of cancer. Usually, for IV, 4, 8, 16, and $20 \mathrm{mg}$ are administered, whereas in oral dosage form, 2-4 $\mathrm{mg}$ are widely used. Variation in the cost of dexamethasone use is different for different patients depending on their disease condition. Metoclopramide and Ondansetron were second and third most utilized antiemetics, respectively. This is not surprising since Ondansetron is the oldest and cheapest among all the $5-\mathrm{HT}_{3}$ antagonists and should be preferred. However, in a similar study carried out in India, Granisetron was more commonly prescribed than Ondansetron (Dave et al., 2012). The National Comprehensive Cancer Network guidelines recommend the use of 5- $\mathrm{HT}_{3}$ antagonists such as Ondansetron as a pharmacological intervention for nausea and vomiting for emetogenic chemotherapy. Metoclopramide is among the oldest antiemetics and is mostly used in high doses to achieve its effects. It is currently recommended in the prophylaxis of acute nausea and vomiting induced by chemotherapy with a low emetogenic potential (Olver et al., 2017). In comparison to other antiemetics, the modest pricing of metoclopramide makes it an important resource in developing countries (Harder and Herrstedt, 2017).

It is important to realize that the inappropriate use of drugs represents a potential hazard to the patients and an unnecessary expense (Kulkarni et al., 2014). It has been established that the branded form of medications is more expensive than the generic form which may prevent the patients from adhering to his medications, especially if he is not able to buy the medicines due to financial constraint (Mugada et al., 2016; Pentareddy et al, 2015). In the present study, the percentage of drugs prescribed in branded form was low. This is an indication that the cost implication of the drugs was put into consideration to enhance patients' affordability, leading to improve compliance and provision of the desired outcome.

The following limitations in addition to those mentioned in the text were inherent in the study and the results were interpreted in this light. Due to the retrospective nature of the study, incomplete data in some prescriptions precluded their inclusion in the study. One tertiary hospital was used and the findings of this study may not be a true reflection of anticancer drug utilization in the entire country.

\section{CONCLUSION}

Cisplatin and Dexamethasone were most utilized anticancer and antiemetic drugs, respectively, for initiation of chemotherapy for both breast and cervical cancers in the studied hospital. Selection of anticancer drugs for initiation of chemotherapy is an important determinant of whether the patient would continue the chemotherapy, switch to another agent, or discontinue after the first course of chemotherapy. Therefore, it is important that attention should be given to the initiating agents, their side effects, and general safety of the patients.

Generic prescription is encouraged, especially in anticancer drugs which are usually expensive. This will reduce the cost of anticancer agents; thus, enhances patients' adherence to medications. Prescription of a cost-effective combination of anticancer agents may be worthwhile. Addition of cytoprotectants and immunomodulatory agents to prescriptions will be helpful considering the adverse drug reactions associated with these anticancer agents.

\section{ACKNOWLEDGMENT}

We acknowledge Pharm. Agunbiade Kehinde Adebayo for his assistance in data collection.

\section{CONFLICT OF INTEREST}

The authors declare no conflict of interest.

\section{FUNDING}

The study was funded by the authors, there was no external funding.

\section{REFERENCES}

Akram A, Malik FA, Kayani MA. Mutational analysis of the MTHFR gene in breast cancer patients of Pakistani population. Asian Pac J Prev, 2012; 13:1599-603; doi:10.7314/apjcp.2012.13.4.1599.

Amin KA, Mohamed BM, El-wakil MAM, Ibrahem SO. Breast cancer impact of breast cancer and combination chemotherapy on oxidative stress, hepatic and cardiac markers. J Breast Cancer, 2012; 15:306-12; doi:10.4048/jbc.2012.15.3.306.

Anisimov V. The relationship between aging and carcinogenesis: a critical appraisal. Crit Rev Oncol Hematol, 2003; 45:277-304; doi:10.1016/s1040-8428(02)00121-x.

Boyle P, Levin B. World Cancer Report 2014. World Cancer Report, Geneva, p. 630, 2014

Dave DJ, Pillai A, Shah DV, Agarwal S, Goel A. An analysis of utilization pattern of anticancer drugs in diagnosed cases $\mathrm{f}$ carcinoma in a tertiary care teaching hospital. Int J Basic Appl Med Sci, 2014; 4(1): 251-259.

Chauvin C, Madec F, Guillemot D, Sanders P. The crucial question of standardization when measuring drug consumption Vet Res BioMed Central, 2001; 32(6):533-43; Available via https://hal.archives-ouvertes.fr/hal-00902729.

Ferlay J, Shin HR, Bray F, Forman D, Mathers C, Parkin DM. Estimates of worldwide burden of cancer in 2008: GLOBOCAN 2008. Int J Cancer, 2010; 127:2893-917; doi:10.1002/ijc.25516.

Fulda TR, Lyles A, Pugh MC, Dale B. Current status of prospective drug utilization review. J Manage Care Pharm, 2004; 10:433-41; doi:10.18553/jmcp.2004.10.5.433.

Grunberg SM. Antiemetic activity of corticosteroids in patients receiving cancer chemotherapy: dosing, efficacy, and tolerability analysis Ann Oncol, 2007; 18:233-40; doi:10.1093/annonc/mdl347.

Gündüz E, Gülbas Z. Supportive care in hemato-oncology: a review in light of the latest guidelines. Turk J Haematol, 2012; 29:1-9; doi:10.5505/tjh.2012.10327.

Harder SL, Herrstedt J. Metoclopramide: an antiemetic in chemotherapy induced nausea and vomiting. J Drug Des Res, 2017; 4:1037-43.

Krtolica A, Campisi J. Cancer and aging: a model for the cancerpromoting effects of the aging stroma. Int J Biochem Cell Biol, 2002; 34:1401-14; doi:10.1016/s1357 2725(02)000 53-5.

Kulkarni MD, Hussaini SA, Padwal SL, Khandelwal PN, Doifode SM, More PP. Drug utilization review of anticancer drugs in cancer outpatient department of the Government Medical College, Aurangabad. IJBCP Int J Basic Clin Pharm, 2014; 3:879-83; doi:10.5455/2319-2003. ijbcp20141030.

Mayer LD, Janoff AS. Optimizing combination chemotherapy by controlling drug ratios. Mol Interven, 2007; 7:216-23; doi:10.1124/ mi.7.4.8.

Merlo J, Wessling A, Melander A. Comparison of dose standard units for drug utilisation studies. Eur J Clin Pharmacol, 1996; 50 (1-2):27-30.

Mugada V, Paruchuri A, Munagala M. Drug utilization evaluation of anticancer drugs in a tertiary care teaching hospital : a descriptive 
observational study. J Appl Pharm Sci, 2016; 6:98-101; doi:10.7324/ japs.2016.601013.

Navari MR. Overview of the updated antiemetic guidelines for chemotherapy-induced nausea and vomiting. Commun Oncol, 2007; 4:3-11.

Olver I, Ruhlmann CH, Jahn F, Schwartzberg L, Rapoport B, Rittenberg CN, Clark-Snow R. 2016 updated MASCC/ESMO consensus recommendations: controlling nausea and vomiting with chemotherapy of low or minimal emetic potential. Support Care Cancer, 2017; 25:297-301.

Ondansetron versus metoclopramide, both combined with dexamethasone, in the prevention of cisplatin-induced delayed emesis. The Italian Group for Antiemetic Research. J Clin Oncol, 1997; 15:124-30; doi:10.1200/jco.1997.15.1.124.

Pentareddy MR, Suresh AVS, Shailendra D, Subbaratnam Y, Prasuna G, Naresh DTV, Rajshekar K. Prescription pattern of anticancer drugs in a tertiary care hospital. J Evid Based Med Healthcare, 2015; 2:3001-9; doi:10.18410/jebmh/2015/435

Polyak K. On the birth of cancer. Biochim Biophys Acta, 2001; 1:1-13; doi:10.1016/s0304-419x(01)00029-4.

Raveh D, Muallem-Zilcha E, Greenberg A, Wiener-Well Y, Schlesinger Y, Yinnon AM. Prospective drug utilization evaluation of three broad-spectrum antimicrobials: Cefepime, piperacillin, tazobactam and meropenem. QJM, 2006; 99:397-406; doi:10.1093/qjmed/hc1050.

Ried LD, Johnson RE. Evaluation of the reliability and validity of a measure of anxiolytic druguse intensity for pharmacoepidemiologic studies. Ann Pharmacother, 1992; 11:1441-6.

Russo F, Linsalata M, Clemente C, D'Attoma B, Orlando A, Campanella G, Giotta F, Riezzo G. The effects of fluorouracil, epirubicin, and cyclophosphamide (FEC60) on the intestinal barrier function and gut peptides in breast cancer patients: an observational study. BMC Cancer, 2013; 13:56; doi:10.1186/1471-2407-13-56.
Silva MF, Tosello C, Laloni MT, Andrade CM, Bertozzi A, Vernaglia P, Correa FM, Moraes RP, Goes JS. FEC 60 adjuvant chemotherapy (AdCT) in breast cancer (BC) patients (Pts): 10-year follow-up results. J Clin Oncol, 2006; 24(18S):835; doi:10.1200/ jco.2004.22.90140.835.

Sylla BS, Wild CP. A million africans a year dying from cancer by 2030: What can cancer research and control offer to the continent? Int J Cancer, 2012; 130:245-50; doi:10.1002/ijc.26333.

Vrabel M. Is ondansetron more effective than granisetron for chemotherapy-induced nausea and vomiting? A review of comparative trials. Clin J Oncol Nurs, 2007; 11:809-13; doi:10.1188/07.cjon.809-813.

Wessling A, Boëthius G. Measurement of drug use in a defined population. Evaluation of the defined daily dose (DDD) methodology. Eur J Clin Pharmacol, 1990; 39:207-10.

Wiebe E, Denny L, Thomas G. Cancer of the cervix uteri. Int J Gynecol Obstet, 2012; 119(SUPPL. 2):S100-S109; doi:10.1016/s00207292 (12)60023-x. Geneva, 2017.

World Health Organization. WHO | cancer factsheet. WHO,

How to cite this article:

Adibe MO, Aluh DO, Ma'aji HU. Anticancer drugs utilization for initiation phase of breast and cervical cancers chemotherapies in a Nigerian tertiary hospital. J Appl Pharm Sci, 2019; 9(03):111-116. 